\title{
As Repercussões do Processo de Internação em UTI Adulto na Perspectiva de Familiares
}

\author{
Larissa Cabral Crespi Reis ${ }^{1}$ \\ Programa de Residência Integrada Multiprofissional em Saúde da Universidade Federal \\ de Santa Catarina, Florianópolis, SC, Brasil \\ Letícia Macedo Gabarra \\ Universidade Federal de Santa Catarina, Florianópolis, SC, Brasil \\ Carmen Leontina Ojeda Ocampo Moré \\ Departamento de Psicologia da Universidade Federal de Santa Catarina, \\ Florianópolis, SC, Brasil
}

\section{Resumo}

A Unidade de Terapia Intensiva (UTI) é um contexto de alta complexidade destinado a pacientes que necessitam de cuidados intensivos. A internação nessa unidade desestabiliza física e emocionalmente não apenas o sujeito internado, mas toda a família. O objetivo desse estudo foi compreender as repercussões do processo de internação em UTI Adulto na perspectiva de familiares. A pesquisa é de natureza qualitativa e foi realizada na UTI Adulto de um hospital geral, de ensino e público. Foram realizadas entrevistas semiestruturadas com doze familiares de pacientes internados na unidade, que foram analisadas com base na Análise de Conteúdo. Os resultados foram divididos em quatro categorias: significados atribuídos à internação na UTI, comunicação equipe-família, a experiência da visita ao leito e, o impacto no cotidiano dos familiares. A hospitalização nesse contexto envolve diretamente os familiares que vivenciam essa experiência e modifica suas vidas. Percebeu-se a necessidade de ampliar o foco do cuidado para além dos pacientes, voltando-se a atenção também para as famílias, com a realização de outros estudos será possível melhorar a assistência prestada a elas.

Palavras-chave: Unidades de Terapia Intensiva, impacto psicossocial, família, relações familiares, relações profissional-família.

\section{The Repercussions of the Hospitalization Process in Adult ICU in Family Perspective}

\begin{abstract}
The Intensive Care Unit (ICU) is a context of high complexity intended to patients requiring intensive care. The hospitalization in this Unit destabilizes physically and emotionally not only the subject internee, but the whole family. The aim of this study was to understand the repercussions of the hospitalization process in an adult ICU with a view to family. The research is qualitative and was held in an adult ICU of a general hospital, educational and public. It were performed semi-structured interviews with twelve family members of patients internee in the unit, which were analyzed based on content analysis. The results were divided into four categories: meanings attributed to the ICU, communication team-family, the experience of the visit to the bed and, the impact on the daily life of the family. Hospi-
\end{abstract}

Endereço para correspondência: Rua Professora Maria Flora Pausewang, s/n, Trindade, Florianópolis, SC, Brasil 88036-800. Fone: (48) 3721-8080. E-mail: laarissacabral@hotmail.com 
talizations in this context directly involve family members who living this experience and change their lives. It was realize the need to broaden the focus of care in addition to patients, turning attention also for families, with further studies should increase the assistance provided to them.

Keywords: Intensive Care Units, psychosocial impact, family, family relations, professional-family relations.

\section{Los Efectos del Proceso de Hospitalización en UCI Adulto en Perspectiva de la Familia}

\section{Resumen}

La Unidad de Cuidados Intensivos (UCI) es un contexto de alta complejidad para los pacientes que requieren cuidados intensivos. La hospitalización en esta Unidad desestabiliza física y emocionalmente no sólo el sujeto hospitalizado, pero toda la familia. El objetivo de este estudio fue comprender los efectos del proceso de hospitalización en la UCI de adultos, en la perspectiva de los miembros de la familia. La investigación es de naturaleza cualitativa y se realizó en una UCI de adultos de un hospital general, educativo y público. Se realizaron entrevistas semi-estructuradas con doce miembros de la familia de los pacientes en la unidad, que fueron analizados con base en el análisis de contenido. Los resultados se dividieron en cuatro categorías: significados atribuidos a la UCI, comunicación equipo-familia, la experiencia de la visita a la cama y, el impacto en la vida cotidiana de la familia. La hospitalización en este contexto implica directamente a miembros de la familia que sufren esta experiencia y cambian sus vidas. Se observó la necesidad de ampliar el foco de atención, además de los pacientes, volver la atención también para las familias, con otros estudios deben aumentar la asistencia que se les proporciona.

Palabras clave: Unidades de Cuidados Intensivos, impacto psicosocial, familia, relaciones familiares, relaciones profesional-familia.

A Unidade de Terapia Intensiva (UTI) é um contexto de alta complexidade, no que diz respeito às tecnologias, ao custo financeiro e à equipe multidisciplinar especializada, destinado a pacientes graves que necessitam desses cuidados (Lima, Amazonas, Barreto, \& Menezes, 2013). Socialmente é considerada um local pouco acolhedor (Freitas, Mussi, \& Menezes, 2012; Severo \& Girardon-Perlini, 2005; Vieira, Matos, Andrade-Barbosa, \& Xavier-Gomes, 2013) e, frequentemente, associada à morte ou doença grave, e por outro lado, relacionada com atenção integral, recuperação e reencontro com a vida (Ismael, 2004; Nieweglowski \& Moré, 2008; Severo \& Girardon-Perlini, 2005). A esse duplo significado presente nessa unidade hospitalar, Nieweglowski e Moré (2008, p. 112) atribuem a metáfora de "ponte entre a vida e a morte". Na UTI os estressores comuns à internação ficam ainda mais exacerbados devido às concepções sociais citadas e a peculiaridades, como a limitação de horários de visita, a restrição dos momentos de comunicação da família com a equipe (Nieweglowski \& Moré, 2008; Vieira et al., 2013; Zanetti, Stumm, \& Ubessi, 2013) e a exposição excessiva e permanente do corpo do paciente (Severo \& Girardon-Perlini, 2005).

A hospitalização em UTI constitui-se em um evento vital estressor e desestabiliza física e emocionalmente toda a família (Freitas et al., 2012; Lima et al., 2013; Silva, 2007), que sofre junto e precisa aprender, com a ausência do membro doente, a viver com a interrupção momentânea ou definitiva da rotina familiar, tendo, de certo modo, sua perda antecipada. Dessa forma, os envolvidos no processo de internação em UTI convivem constantemente com sentimentos ${ }^{2}$ de tensão, angústia, estresse,

\footnotetext{
A palavra "sentimento" foi utilizada aqui com fins de fidelidade aos autores, no entanto optou-se no presente artigo por utilizar a palavra "emo-
} 
ansiedade, raiva, medo e depressão (Ismael, 2004; McAdam, Dracup, White, Fontaine, \& Puntillo, 2010; Nieweglowski \& Moré, 2008; Severo \& Girardon-Perlini, 2005) e necessitam desenvolver estratégias de enfrentamento para lidar com a situação de crise (Nieweglowski \& Moré, 2008; Zanetti et al., 2013).

O estudo realizado por Lima et al. (2013) com familiares de pacientes internados em UTI evidenciou, dentre outros resultados, que as principais preocupações e dificuldades deles são a preocupação com a morte, com a qualidade de vida após a alta, com o curto período de tempo para visitas e com os cuidados prestados pela equipe. Por outro lado, verificou que alguns dos aspectos positivos da internação são o crescimento pessoal e profissional e o aumento da espiritualidade, essa última identificada na pesquisa de Zanetti et al. (2013) como a principal estratégia de enfrentamento utilizada por familiares. Dessa forma, a hospitalização pode ser considerada também como contexto de desenvolvimento individual e familiar (Barros, 2003).

Os desconfortos vivenciados pelas famílias podem ser minimizados através de uma comunicação acolhedora e solidária por parte da equipe, com informações realistas e claras, mas sem lhes tirar a confiança (Freitas et al., 2012; Ismael, 2004). Informar os familiares sobre as decisões terapêuticas que podem afetar o paciente pode ser uma forma de cuidado com eles (McAdam et al., 2010). Bowen (1998) chama de relacionamento aberto aquele no qual há liberdade para a expressão de pensamentos, sentimentos e fantasias de forma recíproca e salienta que, no diálogo entre equipe e família, a ansiedade do profissional é inversamente proporcional a sua capacidade de escutar.

O estudo realizado por Morgon e Guirardello (2004) validou em uma escala as principais

ção", por ter-se considerado mais apropriada para a situação de hospitalização, conforme definição de Dalgalarrondo (2008, p. 156), onde "emoções são reações afetivas agudas, momentâneas, desencadeadas por estímulos significativos", sendo "ao mesmo tempo, experiências psíquicas e somáticas". necessidades dos familiares em UTI: Sentir que a equipe se interessa pelo paciente, estar seguro de que o melhor tratamento possível está sendo dado a ele, sentir que há esperança de melhora, saber que tratamento está sendo dado e, ter perguntas respondidas com franqueza. A maioria dos resultados da pesquisa citada está relacionada com o boletim médico, que é o momento que o profissional informa às famílias sobre as condições de saúde do doente, prognóstico e propostas terapêuticas.

A pesquisa realizada por Lima et al. (2013) identificou que os familiares manifestaram maior satisfação com os cuidados prestados ao paciente quando entendiam melhor as explicações sobre a condição clínica dele, evitando assim conflitos, angústias e dúvidas. Situação inversa foi encontrada no estudo realizado por Nieweglowski e Moré (2008) em uma UTI Pediátrica, o qual verificou que a falta de informações gerou incertezas nos familiares, reduzindo suas capacidades de enfrentamento e contribuindo para uma compreensão desfavorável e equivocada do prognóstico. Nesse sentido, evidenciou-se a relação direta da comunicação entre equipe e família com a qualidade do trabalho dos profissionais e com o grau de sofrimento dos envolvidos.

O diálogo em UTI é afetada pelas situações que envolvem o processo de internação e podem dificultar a comunicação efetiva (Nieweglowski \& Moré, 2008). A família muitas vezes "seleciona" o que é menos difícil de assimilar emocionalmente naquele momento (Ismael, 2004), o que pode demandar a repetição das mesmas informações inúmeras vezes por parte da equipe (Ismael, 2004; Nieweglowski \& Moré, 2008).

Além de uma comunicação satisfatória, a família frente à hospitalização de um dos seus membros sente a necessidade de estar próxima dele (Freitas et al., 2012; Lima et al., 2013). $\mathrm{O}$ sujeito internado sente-se mais seguro com a presença do familiar (Severo \& Girardon-Perlini, 2005), além de responder melhor ao tratamento quando estabelece uma maior afetividade com sua rede social (Freitas et al., 2012; Ministério da Saúde, 2008). Os familiares parecem vivenciar, em relação à visita ao 
leito, o desejo de estar com o paciente e a preocupação com a redução dos horários de visita na UTI (Lima et al., 2013; Nieweglowski \& Moré, 2008); e, ao mesmo tempo, dificuldade em ver o sofrimento do doente (Freitas et al., 2012; Nieweglowski \& Moré, 2008), assustando-se também com a presença dos aparelhos, como os de ventilação mecânica (Silva, 2007).

A visita dos familiares na Unidade propicia, ainda, o encontro com os familiares de outros pacientes, o que pode dificultar a experiência da internação devido à comparação entre os quadros de saúde e a gravidade de cada caso (Nieweglowski \& Moré, 2008) ou funcionar como mecanismo de enfrentamento por meio do compartilhamento de experiências, formando uma rede de apoio comum, o que foi identificado na pesquisa de Molina, Higarashi e Marcon (2014) com mães de crianças internadas em UTI Pediátrica.

Os efeitos da internação em UTI não se limitam apenas ao contexto hospitalar, mas envolvem mudanças em todo o cotidiano familiar (Freitas et al., 2012; Ismael, 2004; Zanetti et al., 2013). Alguns estudos (Freitas et al., 2012; Lima et al., 2013) verificaram interferência nas atividades diárias, sociais e profissionais e mudanças nos papéis e nos comportamentos dos familiares. A hospitalização influencia diretamente no autocuidado dos envolvidos, que podem ficar horas sem dormir e se alimentar adequadamente a espera de informações acerca do sujeito doente (Ismael, 2004).

Essas pessoas vivenciam o estresse não somente pela hospitalização do seu ente, mas também pelas suas atividades diárias que as sobrecarregam (Zanetti et al., 2013). Algumas mudanças na família são necessárias a partir da internação para atender as demandas exigidas pelas circunstâncias (Freitas et al., 2012; Ismael, 2004; Zanetti et al., 2013). Essa experiência é capaz de modificar o movimento em que os familiares se encontram, podendo provocar uma "força centrípeta", ou seja, a família se volta para a doença e/ou para o doente, mesmo quando se encontra num período de afastamento (Rolland, 1995). As transformações ocorrem também com relação à redefinição de papéis dentro da dinâmi- ca familiar, necessária para reorganizar o sistema na situação de crise (Ismael, 2004; Rolland, 1995).

A pesquisa de Lima et al. (2013) evidenciou que a hospitalização afetou as rotinas dos familiares, que relataram desmotivação para as atividades diárias e mudanças de papéis entre os seus membros. O mesmo foi encontrado no estudo de Freitas et al. (2012), o qual verificou que, com a internação em UTI, as famílias sofreram uma descontinuidade na vida expressada pelos desconfortos da angústia da possibilidade de morte do doente; da cisão no cotidiano familiar, mudando o comportamento entre eles pelo desgaste físico e emocional e afastando-se do lar; e das dificuldades para cuidar de si, tendo o sono e a alimentação prejudicados. Ambas as pesquisas identificaram, ainda, interferências na vida social e profissional dos entrevistados.

Visto que o sofrimento dos familiares interfere diretamente na recuperação dos pacientes e na saúde física e mental de ambos, se faz necessário direcionar o olhar para eles. Portanto, discutir esse tema pode desencadear reflexões e ações por parte da equipe para que compreenda melhor a experiência da família, culminando numa melhor assistência multiprofissional em UTI (Nieweglowski \& Moré, 2008; Zanetti et al., 2013).

Ancorado nas questões acima, o presente artigo pretende compreender as repercussões do processo de internação em UTI Adulto na perspectiva de familiares. Para isso, buscou-se: Identificar o impacto da notícia da internação em UTI nos familiares; descrever as vivências dos familiares ao receberem os boletins médicos; analisar as experiências dos familiares relacionadas às visitas ao paciente no leito; e identificar as mudanças no cotidiano familiar decorrentes da internação em UTI na perspectiva dos participantes.

\section{Método}

O presente estudo, descritivo, de caráter transversal e natureza qualitativa, foi realizado na UTI Adulto, de um hospital geral de ensino, exclusivamente público, localizado no Sul do 
Brasil. A Unidade dispunha de 15 leitos ativos e era aberta para visitas em três horários nos diferentes períodos do dia, sendo um concomitante ao boletim médico e os familiares aguardavam em bancos no corredor em frente à entrada da UTI. A equipe era composta por enfermeiros, técnicos de enfermagem, médicos, fisioterapeutas, fonoaudiólogas, nutricionista, psicóloga, assistente social e residentes de medicina e multiprofissionais.

A pesquisa teve início após ser aprovada pelo Comitê de Ética para Pesquisas com Seres Humanos da instituição (CAAE 32936214.4.0000.0121, parecer $\mathrm{n}^{\mathrm{o}}$ 724.402). Todos os aspectos contidos na Resolução $\mathrm{n}^{\circ}$ 466/2012 do Conselho Nacional de Saúde e no Código de Ética Profissional do Psicólogo de 2005 foram respeitados para a garantia de proteção dos participantes. Além dos nomes dos sujeitos terem sido preservados, utilizando-se de letra e números para identificá-los.

$\mathrm{O}$ instrumento utilizado foi uma entrevista semiestruturada constituída de duas partes: a primeira com questões de caracterização do paciente e do participante, para a qual foram utilizados dados dos Prontuários Hospitalares como diagnósticos, história de saúde e tempo de internação; e a segunda contendo cinco questões abertas relacionadas aos objetivos do trabalho e elaborado a partir da teoria e das informações sobre o fenômeno pesquisado. Foram realizadas quatro entrevistas de sensibilização do instrumento, a fim de aperfeiçoar o roteiro, e a coleta de dados ocorreu de agosto a setembro de 2014.

A abordagem aos possíveis participantes ocorreu no período de espera para as visitas, quando foram apresentados ao estudo. Com as pessoas que demonstravam interesse em participar, era agendado um horário em sala reservada da UTI para a leitura do Termo de Consentimento Livre e Esclarecido e, após aceite em participar da pesquisa e assinaturas de ambas as partes, dava-se início às entrevistas, que foram gravadas e transcritas integralmente.

O fim da coleta de dados ocorreu devido à sua saturação, ou seja, a observação do momento em que as informações obtidas começaram a apresentar regularidade e frequência em torno do objetivo proposto (Fontanella, Ricas, \& Turato, 2008). No caso do presente trabalho, observou-se que a saturação iniciou na sétima entrevista e foram realizadas doze a fim de confirmá-la. Esse número de sujeitos vai ao encontro do resultado do estudo de Guest, Bunce e Johnson (2006), que concluiu que a saturação, em sua maior parte, ocorre na entrevista de número doze.

Os dados coletados foram analisados com base na Análise de Conteúdo, proposta por Bardin (1977), que abarca três fases: Pré-análise, que envolve a leitura flutuante de todas as transcrições das entrevistas; a exploração do material, na qual se formam categorias e subcategorias; e o tratamento dos resultados, onde os dados são interpretados.

Os participantes desta pesquisa foram familiares de pacientes internados na UTI, considerando família como grupo de pessoas que se considera dessa forma, ou seja, "a família é quem dizem que são"3 (Wright \& Leahey, 2013, p. 55). Por isso, após apresentada a proposta do estudo, foi questionado aos próprios familiares quem deveria ser entrevistado. Foram convidadas dezoito pessoas a participar do estudo, sendo que desses, seis não aceitaram. Os sujeitos do trabalho foram, então, doze familiares de pacientes internados na UTI que satisfizeram os critérios de inclusão: idade igual ou superior a 18 anos, ter um familiar na Unidade no mínimo há 48 horas, visitar e participar do processo de internação e aceitar expressar a sua experiência e os seus sentimentos.

\section{Resultados e Discussão}

Todos os participantes eram adultos, maioria homens, com idades que variaram entre $29 \mathrm{e}$ 68 (média: 47,5) e os graus de parentesco com o paciente eram de esposos, pais, irmãs e filhos. As principais características dos participantes estão apresentadas na Tabela 1.

3 Tradução do autor: "the family is who they say they are" (Wright \& Leahey, 2013, p. 55). 
Tabela 1

Apresentação das Principais Características dos Participantes

\begin{tabular}{ccccc}
\hline Participante & Idade & Sexo & Grau de parentesco & Frequência de visita \\
\hline P1 & 61 & F & Esposa & $1 \mathrm{x} /$ dia \\
P2 & 40 & F & Filha & $1 \mathrm{x} /$ dia \\
P3 & 43 & M & Pai & $2 \mathrm{a} 3 \mathrm{x} /$ dia \\
P4 & 56 & M & Filho (único & $3 \mathrm{x} /$ dia \\
P5 & 50 & M & Filho & $2 \mathrm{x} /$ dia \\
P6 & 38 & M & Esposo & $1 \mathrm{x} /$ dia \\
P7 & 59 & M & Pai & $3 \mathrm{x} /$ dia \\
P8 & 29 & M & Filho & $1 \mathrm{x} /$ dia \\
P9 & 68 & M & Pai & $1 \mathrm{a} 2 \mathrm{x} /$ dia \\
P10 & 55 & F & Irmã & $1 \mathrm{x} /$ dia \\
P11 & 30 & F & Esposa & $3 \mathrm{x} /$ dia \\
P12 & 42 & F & Irmã & $2 \mathrm{x} /$ dia \\
\hline
\end{tabular}

Tabela 2

Apresentação das Principais Características dos Pacientes Internados na UTI

\begin{tabular}{|c|c|c|c|c|c|c|}
\hline Paciente & Idade & Sexo & $\begin{array}{c}\text { Motivo } \\
\text { da internação } \\
\text { na UTI }\end{array}$ & $\begin{array}{l}\text { História } \\
\text { de saúde }\end{array}$ & $\begin{array}{c}\text { Dias de } \\
\text { internação } \\
\text { na UTI }\end{array}$ & $\begin{array}{c}\text { Internações } \\
\text { prévias } \\
\text { em UTI }\end{array}$ \\
\hline $\mathrm{P} 1$ & 18 & M & $\begin{array}{l}\text { Intercorrência } \\
\text { em pós-operatório }\end{array}$ & $\begin{array}{l}\text { Doença } \\
\text { crônica }\end{array}$ & 10 & 2 \\
\hline P2 & 68 & $\mathrm{~F}$ & $\begin{array}{l}\text { Monitorização } \\
\text { pós-operatório }\end{array}$ & $\begin{array}{l}\text { Doença } \\
\text { crônica }\end{array}$ & 2 & 0 \\
\hline P3 & 24 & M & Doença aguda & $\begin{array}{l}\text { Cirurgia } \\
\text { prévia }\end{array}$ & 24 & 5 \\
\hline P4 & 86 & $\mathrm{~F}$ & $\begin{array}{l}\text { Monitorização } \\
\text { pós-operatório }\end{array}$ & $\begin{array}{l}\text { Doença } \\
\text { crônica }\end{array}$ & 3 & 0 \\
\hline P5 & 82 & $\mathrm{~F}$ & $\begin{array}{l}\text { Doença crônica } \\
\text { agudizada }\end{array}$ & $\begin{array}{c}\text { Doenças crônicas } \\
\text { e agudas }\end{array}$ & 3 & 1 \\
\hline P6 & 41 & $\mathrm{~F}$ & $\begin{array}{l}\text { Doença crônica } \\
\text { agudizada }\end{array}$ & $\begin{array}{c}\text { Doenças crônicas } \\
\text { e agudas }\end{array}$ & 4 & 0 \\
\hline P7 & 30 & $\mathrm{~F}$ & $\begin{array}{l}\text { Doença crônica } \\
\text { agudizada }\end{array}$ & $\begin{array}{c}\text { Doenças crônicas } \\
\text { e agudas }\end{array}$ & 6 & 1 \\
\hline P8 & 72 & M & $\begin{array}{l}\text { Monitorização } \\
\text { pós-operatório }\end{array}$ & Doenças crônicas & 8 & 0 \\
\hline P9 & 18 & $\mathrm{~F}$ & Doença aguda & $\begin{array}{l}\text { Doença } \\
\text { crônica }\end{array}$ & 10 & 0 \\
\hline P10 & 52 & M & Doença aguda & $\begin{array}{l}\text { Cirurgia prévia e } \\
\text { doenças crônicas }\end{array}$ & 13 & 0 \\
\hline P11 & 34 & M & $\begin{array}{l}\text { Monitorização } \\
\text { pós-operatório }\end{array}$ & $\begin{array}{l}\text { Sem história de } \\
\text { doença }\end{array}$ & 3 & 2 \\
\hline P12 & 32 & M & Doença aguda & $\begin{array}{c}\text { Doenças } \\
\text { agudas }\end{array}$ & 3 & 0 \\
\hline
\end{tabular}


Cabe apontar que as informações sobre a "frequência de visitas" foram fornecidas pelos próprios participantes, que foram selecionados pelas famílias como sendo os membros mais próximos ao paciente e mais participativos no processo de internação.

Faz-se importante caracterizar, ainda, os pacientes, visto que tais aspectos interferem diretamente na vivência da internação por parte dos familiares. As idades variaram entre 18 e 86

Tabela 3

Apresentação das Categorias e Subcategorias (média: 46,4) e estavam na UTI por intercorrências ou monitorização de pós-operatório-ou por doenças agudas ou crônicas agudizadas. A média do tempo de internação na Unidade foi de 7,4 dias e a maioria não possuía internações prévias em UTI. A Tabela 2 mostra as principais características dos pacientes.

Após a análise dos dados, os resultados foram agrupados nas seguintes categorias e subcategorias, conforme Tabela 3, e apresentados e discutidos posteriormente.

\begin{tabular}{|c|c|}
\hline Categorias & Subcategorias \\
\hline 1. Significados atribuídos à internação na UTI & $\begin{array}{l}\text { 1.1 Imprevisibilidade } \\
\text { 1.2 Metáfora vida e morte } \\
\text { 1.3 Ressignificação da vida }\end{array}$ \\
\hline 2. Comunicação equipe-família & $\begin{array}{l}\text { 2.1 Comunicação aberta } \\
\text { 2.2 Relação de cuidado } \\
\text { 2.3 Boletim médico }\end{array}$ \\
\hline 3. A experiência da visita ao leito & $\begin{array}{l}\text { 3.1 Aspectos ambientais } \\
\text { 3.2 Companhia do paciente }\end{array}$ \\
\hline 4. O impacto no cotidiano dos familiares & $\begin{array}{l}\text { 4.1 Atividades de vida diárias } \\
\text { 4.2 Movimento centrípeto } \\
\text { 4.3 Repercussões emocionais } \\
\text { 4.4 Planos pós-alta }\end{array}$ \\
\hline
\end{tabular}

\section{Significados Atribuídos à Internação na UTI}

Nessa categoria congregaram-se os significados atribuídos à UTI, resultantes do impacto da notícia da internação, assim como do processo de internação propriamente dito.

Imprevisibilidade. Alguns dos entrevistados relataram ansiedade relacionada à imprevisibilidade presente na UTI, à necessidade de ter paciência e à incerteza quanto à recuperação $\mathrm{e}$ quanto ao futuro, resultado encontrado também na pesquisa de Freitas et al. (2012). Os sujeitos demonstraram em seus discursos ser esse um aspecto importante do impacto tanto da notícia da internação, quanto de todo o período vivenciado na Unidade: “. . . a gente sempre chega aqui com o coração na mão, não sabe se vai tá bom, se não vai tá, se vai sair, se não vai. Então, é agoniante" ( $\mathrm{P} 3)$.
Metáfora Vida e Morte. O discurso dos participantes revelou uma associação importante de UTI com a temática de vida e morte. Esta apareceu focalizada na chance de viver, no medo da perda, ou ainda, na ambivalência entre ambos.

Parte dos sujeitos demonstrou relacionar essa Unidade com chance de viver:

Eu me senti aliviado, porque se ela tá lá [na Emergência] eu sei que ela já tinha ido. Então eu sei que a UTI, "ah, UTI assusta", mas eu sei que é um quarto de melhoria, eu sei que quem sobe pra UTI é porque lá vai ter mais chance... (P5)

Corroborando com os autores Severo e Girardon-Perlini (2005) que trazem a concepção social de UTI relacionada com atenção integral, recuperação e reencontro com a vida. Por outro lado, alguns entrevistados associaram essa Unidade com morte ou doença grave, o que pode ser 
ilustrado pela fala de um participante que afirmou que seu filho estava "internado pra morrer" (P3). Apareceu também na forma da preocupação com o prolongamento da internação e, ainda, na esperança pela alta:

Eu fico meio assustada porque uma UTI é uma palavra assim muito forte, porque ali a gente pensa: "pô, ele tá aqui porque ele tá em alto risco, ele tá em risco de falecer". É, por isso que, quando eu falo que quero que ele vá pro quarto, parece que lá no quarto ele tá fora de perigo, que do quarto ele já vai pra casa. Daí eu penso que quanto mais rápido ele sair da UTI pra mim é um conforto no meu coração . . . (P11)

Outros participantes demonstraram, ainda, ambivalência entre vida e morte ao pensar na UTI, e referiram à desmistificação desse contexto durante o processo de internação:

É que, na verdade, eu nunca vim numa UTI, então só ouvia as pessoas falar, então nem tudo que os outros falam é verdade, sabe. . . . eu achava que quem tá na UTI ia morrer, tá entre a vida e a morte, mas não é assim, porque ela tá aqui pra ter um cuidado de perto... (P6)

Os sujeitos envolvidos na internação em UTI utilizam da metáfora da vida e da morte para se referir à experiência vivenciada, que traz consigo um duplo sentido e é associada tanto com o viver, na forma do cuidado, quanto com o morrer (Ismael, 2004; Nieweglowski \& Moré, 2008; Severo \& Girardon-Perlini, 2005).

Ressignificação da Vida. Os participantes relataram uma ressignificação das suas vidas e dos seus valores, a partir da internação, alguns manifestando, inclusive, arrependimento por atitudes anteriores, além do desejo de que a experiência traga mudanças também para o paciente: . . . a gente vai fazendo as coisas meio que no automático e esquece de dar um pouco mais de valor na vida, né, e a vida da gente é muito importante. . . quando acontece tudo isso aí a gente acaba, pá, parece que levando um choque pra vida e vendo que nada que você faz . . . é tão importante quanto você dar valor pra vida . . . (P3)

Percebeu-se que o crescimento pessoal é um dos aspectos positivos da internação em UTI, como identificado por Lima et al. (2013). A literatura oferece a ideia de que estressores podem provocar o desenvolvimento humano individual e familiar. Nesse sentido, o contexto hospitalar pode propiciar a revisão da vida e das relações, provocando mudanças mesmo que temporárias (Barros, 2003).

\section{Comunicação Equipe-Família}

A forma como se dá a comunicação entre equipe e família teve papel crucial no processo emocional vivenciado pelos familiares durante a internação, podendo exercer uma dupla função: exacerbar ou minimizar o sofrimento deles.

Comunicação Aberta. Os participantes demonstraram anseio por informações honestas e diretas, por explicações sobre os procedimentos e por sentir abertura para o esclarecimento de dúvidas, o que gerou tranquilidade e conforto nos familiares: ". . . doutora muito eficiente, me acalmou, me tranquilizou, sempre se comunicou honestamente, abertamente de todos os riscos que podia ter e do que era o procedimento que tava sendo tomado..." (P3).

A comunicação equipe-família também mostrou impacto importante no momento de informar sobre a internação na UTI. Observou-se que, quando a notícia foi dada de forma aberta, isto é, esclarecendo os motivos da internação e desmistificando a Unidade, os sujeitos sentiram-se mais tranquilos e desejosos pela internação. Por outro lado, quando foi passada de forma súbita e sem as explicações necessárias gerou ansiedade e medo nos familiares:

... eu perguntei pro médico: "o caso dela é grave assim?", ele disse: "não, o caso dela é grave, ela tem tanto perigo aqui na Emergência quanto lá na UTI, mas ela tando na UTI ela tem mais cuidado, ela tem mais médico perto dela, acompanha de perto tal". Dai ali eu me acalmei, sabe. .. . Fiquei mais confortável, sabe. Daí eu fiquei já com pressa de que ela viesse logo pra cá, pra cuidar melhor, né. (P6)

A forma com que ocorre o diálogo tem efeito decisivo na maior ou menor aceitação da si- 
tuação e pode interferir em toda a vivência da internação. A comunicação efetiva de equipe e família tem relação direta, segundo a literatura, com a satisfação e com o sofrimento dos familiares (Freitas et al., 2012; Lima et al., 2013; Nieweglowski \& Moré, 2008).

Relação de Cuidado. Os sujeitos verbalizaram satisfação com o cuidado e confiança na equipe, sensação de tranquilidade e esperança, além de sentimentos de gratidão:

. . Eu vejo uma atenção muito grande do pessoal aqui, não sei se é porque é um hospital universitário . . . Eles dão uma atenção bem importante não só pro paciente, né, que eu acho que o paciente é o principal, né, mas eu acho que pra nós, eu acho que isso ai é fundamental, isso aí não é uma coisa muito comum, eu já tive em outros hospitais, já tive com pessoas da familia internadas em hospital e nunca vi esse respaldo assim, sabe, essa atenção. ... Não tão fazendo só aquela coisa técnica, né, do profissional ali, eu vejo que eles tem um carinho sabe, é uma coisa mais humana com as pessoas, porque principalmente, o paciente óbvio tá debilitado enfim, mas a família também tá ali ... (P4)

A literatura (McAdam et al., 2010) refere que as informações fornecidas aos familiares sobre a situação do paciente podem ser consideradas uma forma de cuidado com eles. A comunicação adequada pode ser favorecedora da desmistificação do contexto da UTI, visto que socialmente é considerada um local pouco acolhedor (Freitas et al., 2012; Severo \& Girardon-Perlini, 2005; Vieira et al., 2013). A surpresa de ser bem acolhido favorece a humanização e resulta em uma percepção positiva da Unidade por parte da família (Lima et al., 2013).

Boletim Médico. Os entrevistados referiram conforto por receber notícias de quando não estão presentes e por terem um momento reservado para dialogar com o médico, além de explicações de aspectos que, muitas vezes, não possuíam conhecimento. Observou-se que as conversas com os profissionais geraram tranquilidade, alívio e conforto na família e, ainda, maior satisfação quando conseguiam receber as informações pessoalmente, nos casos em que a distância geográfica apenas permitiu o boletim por telefone.

Por sua vez, apareceu nos discursos dos participantes ansiedade e apreensão com o boletim médico devido à sua imprevisibilidade, além da influência da natureza das notícias no estado emocional dos familiares, que ficavam felizes ao receber informações positivas ou tristes com as negativas. A comunicação com o profissional foi considerada um momento que auxilia na preparação familiar para encontrar o paciente (por ocorrer antes da visita) e, ainda, para o óbito iminente. Os entrevistados relataram sentirem-se mais capacitados e fortalecidos após o boletim para informar os demais membros da família sobre a situação do doente.

Alguns sujeitos demonstraram ambivalência entre saber ou não saber sobre a evolução de saúde do seu familiar, tendo participantes que, inclusive, optaram por não participar do boletim médico:

. . . No começo foi muito difícil, porque a gente não quer ouvir, a gente quer ouvir a verdade, mas ao mesmo tempo a gente queria saber só que estivesse a situação cada dia melhor, mas às vezes não é isso que acontece... (P10)

As emoções interferem diretamente na comunicação, dessa forma o diálogo em UTI é afetado pelo estado emocional dos sujeitos, que podem, de certa forma, selecionar o que são capazes de assimilar naquele momento (Ismael, 2004; Nieweglowski \& Moré, 2008) e até mesmo resistir em receber informações, como no caso da participante acima.

Os entrevistados desta pesquisa demonstraram considerar os boletins como um dos momentos mais importantes do processo de internação, indo ao encontro do estudo de Morgon e Guirardello (2004), que identificou que as principais necessidades de famílias em UTI estão relacionadas com o boletim médico. E embora a literatura apresente a restrição dos momentos de comunicação equipe-família como um dos estressores nessa Unidade (Nieweglowski \& Moré, 2008; Vieira et al., 2013; Zanetti et al., 2013), esse aspecto não foi relatado pelos 
participantes como um dificultador, pelo contrário, esses demonstraram satisfação em terem um horário específico destinado a receber informações.

\section{A Experiência da Visita ao Leito}

A visita é vista como um dos momentos de maior expectativa dos familiares de pacientes internados na UTI, que anseiam em vê-los e em manter suas relações mesmo com a distância ocasionada pela situação.

Aspectos Ambientais. Enquanto alguns participantes verbalizaram desconforto com os aparelhos e com o local em si, outros relataram conforto por relacioná-los com cuidados ao paciente. A ventilação mecânica apareceu nos discursos associada com maior gravidade do estado de saúde do doente e, dessa forma, como uma agravante na aflição dos familiares:

. . e embora sabendo que ela não tá sentindo dor, porque eu perguntei pros médicos, eu não me sentia bem de ver ela intubada assim . . a aquilo ali pra mim era ruim, dá vontade de arrancar aquilo né, e eu tava torcendo pra eles fazerem logo a... traqueostomia, pra tirar aquilo da boca dela, né. Parece que tirando aquilo ela vai reagir mais rápido, é o que eu sinto, né. (P9)

Apesar dos desconfortos, a explicação da equipe sobre os aparelhos apareceu como minimizadora deles. Os sujeitos demonstraram aflição também com a situação de ver o familiar internado, e não com o local propriamente dito. A literatura corrobora com os resultados encontrados ao relatar a dificuldade dos familiares em ver o sofrimento do doente e o desconforto gerado pela presença dos aparelhos, especialmente os de ventilação mecânica (Freitas et al., 2012; Nieweglowski \& Moré, 2008; Silva, 2007).

Companhia do Paciente. Os entrevistados demonstraram valorização dos momentos de estar na companhia do doente, alguns referindo, inclusive, pensamento de que cada visita poderia ser a última e buscaram despedir-se. Os familiares relataram o contato verbal e físico com o paciente e as "trocas" que ocorreram durante esses momentos:
. . e eu sinto assim que mesmo que ele esteja ali eu chego, falo com ele assim, de mão na mão ali, é uma troca, mesmo que ele esteja nessa situação. Conto tudo que aconteceu, como as coisas estão e sinto que a vontade dele é se esforçar pra irmos pra casa. (P10) Apareceu nos discursos o rodízio de visitas; a exclusão da visita, por parte da família, principalmente de crianças e de pessoas que pareciam interferir no quadro emocional do doente e; ainda, a maior apreensão de alguns familiares devido à distância geográfica, gerando, inclusive, questionamentos das informações repassadas pelos membros da família presentes fisicamente no processo de internação. Estar na companhia do paciente num contexto de UTI foi observado como situação geradora de ansiedade devido à sensação de despreparo para visitar:

...tu se sente despreparada pra chegar e conversar. Evitar qualquer lágrima e ser positiva, né. Então, a impressão que eu sinto que nós... Eu fui preparada pra vencer, pra... Pras coisas mais positivas da vida. . . . Mas quando você entra pra dentro de um quadro desse, como trazer o positivismo pra pessoa, o que falar, o que dizer, aonde botar a mão, entende? Posso fazer carinho, não posso? Porque, assim, tem momentos de muita raiva que a gente tem que nem abraçada a gente quer ser, e na UTI como é que o paciente se sente? Será que ele se sente bem da gente tá passando a mão no cabelo dele ou, do tipo assim, dá uma repulsa? Como será, entende? Então, você não sabe como se posicionar, o que dizer, o que falar, qual o lugar que eu fico, qual é o meu lugar nesse quarto, né? ... ( $\mathrm{P} 2)$

Os participantes relataram preocupação em como se portar na frente do familiar internado e o que transmitir para ele, demonstrando dificuldade para estabelecer uma comunicação em que se pode conversar abertamente sobre seus anseios e desejos. No entanto, apesar disso, é possível perceber a necessidade que a família sente de estar próxima do paciente, corroborando com a literatura (Freitas et al., 2012; Lima et al., 2013; Nieweglowski \& Moré, 2008). 


\section{O Impacto no Cotidiano dos Familiares}

A internação em UTI ultrapassa os limites do hospital e se reflete em todo o cotidiano dos familiares envolvidos na experiência. Nesta categoria serão apresentados os aspectos do cotidiano familiar que sofreram a interferência da internação, segundo os participantes desta pesquisa.

Atividades de Vida Diárias. Os entrevistados referiram interrupção ou diminuição das atividades profissionais, sociais e de lazer; adequação da rotina para os horários de visita; e aproximação de pessoas que passaram por situações parecidas, essa última identificada na pesquisa de Molina et al. (2014) como mecanismo de enfrentamento da dor e do sofrimento por meio do compartilhamento de experiências.

Também foram citadas a redução da fome e/ ou do apetite e a dificuldade para dormir, sendo necessário, inclusive, iniciar uso de medicação: "... Às vezes não se alimenta em casa, se alimenta no caminho mesmo, vai tocando do jeito que dá. Não se alimenta, não dá pra comer, come na volta ..." (P3). A interferência na alimentação e no sono estiveram presentes principalmente no início da internação e melhoraram conforme evolução positiva do paciente. A literatura relata a interferência da internação em UTI na vida social e profissional, no sono e na alimentação dos familiares (Freitas et al., 2012; Ismael, 2004; Lima et al., 2013).

A frequência com que os participantes visitavam o doente variou de acordo com suas atividades de vida diárias, como trabalho e demais compromissos fora do hospital, e repercutiu na organização de todo o grupo familiar. Observou-se que a frequência da visitação não necessariamente estava relacionada com a maior ou menor participação no processo de internação, visto que muitas vezes a única visita do familiar acontecia no horário do boletim médico e este exercia papel de receber notícias do paciente e repassá-las aos demais familiares, desempenhando função de organizador da família e sendo selecionado por eles próprios como participante da pesquisa.

Os entrevistados relataram o reflexo do estresse da internação nos familiares mais próxi- mos: "Olha, tem horas assim que a gente fica um pouco nervoso, às vezes acaba até descontando em alguém assim . . . Porque tu tá, né, meio nervoso, apreensivo, angustiado ..." (P8). Esse aspecto foi identificado por Freitas et al. (2012) como mudança no comportamento com outras pessoas, e atribuído ao desgaste emocional e físico, à irritabilidade e à impaciência. $\mathrm{O}$ aumento da espiritualidade também apareceu nos discursos dos participantes, corroborando com a literatura e considerada a principal estratégia de enfrentamento utilizada pelos familiares (Lima et al., 2013; Zanetti et al., 2013).

Movimento Centrípeto. Os sujeitos referiram a presença de uma força centrípeta (Rolland, 1995), ou seja, as famílias se voltaram para a situação de internação: “. . . A gente ligava pra saber como é que tava, como é que foi o dia. . querer notícia dos nossos familiares. Agora mudou porque o foco todo é a saúde dele ..." (P10). Observou-se maior união familiar, que se manifestou na preocupação uns com os outros, no apoio financeiro e na mudança de residência entre os familiares:

...é o mal que vem pro bem. . . porque a gente nunca consegue juntar a família e com a doença a gente juntou, então Deus faz tudo certo. Porque antes era um lá, outro cá, outro lá, ninguém se vê, aí quando dá uma doença, aí se une, entende? É igual a morte, a morte é ruim, mas pra muitos é bom. Tem muita família que os irmãos não se fala e através da morte, às vezes de um pai, de uma mãe, de um tio, se une. (P5)

Os participantes relataram maior necessidade de comunicação com os demais membros da família para informar sobre a evolução no quadro clínico do paciente, relatando uma maior frequência de ligações devido à preocupação da família. Os entrevistados demonstraram vivenciar uma ambivalência entre demonstrar e sentir, referindo sentimentos de desesperança e nervosismo, contrapondo-se ao esforço em demonstrar esperança e tranquilidade para o doente e demais familiares, em especial para as crianças:

. . . meus filhos não pode me ver chorando. Ai eu tenho que ligar o chuveiro, me trancar, porque se eu for chorar no quarto eles 
vão escutar, se eu for chorar no banheiro com o chuveiro ligado eles não escutam. Ai lá eu posso chorar o que eu fiquei guardando pra mim, dai pra não deixar eles mais preocupados... (P11)

Os sujeitos referiram, ainda, a redefinição de papéis como manifestação da união familiar. A reorganização da divisão de tarefas apareceu tanto na maior ajuda nas atividades domésticas oferecida ao participante pelos demais, quanto em situações em que ele assumiu em casa função desempenhada pelo paciente: “. . . e ele faz tudo . . f faz comida, ele lava a roupa . . . Agora na realidade ele faz de segunda a segunda, né, e antes ele fazia só sábado e domingo ...."(P2). A redefinição de papéis também foi verificada na pesquisa de Lima et al. (2013), e segundo Ismael (2004) e Rolland (1995), faz parte das modificações familiares e é necessária para organizar o sistema na situação de crise.

Repercussões Emocionais. Foram incluídas nessa subcategoria algumas das emoções despertadas pela experiência da internação em UTI, sobre as quais percebeu-se necessidade de destacar devido à intensidade com que emergiram.

Especialmente com relação ao momento da notícia da internação, os entrevistados referiram o que chamamos de estado de torpor, expressado por algumas frases significativas: "desabou o mundo na minha cabeça" (P7) e, "perdi o chão . .. Aí meu chão se abriu" (P11). A ansiedade demonstrou-se presente durante o dia a dia dos familiares, estando relacionada especialmente com os momentos de visita e de boletim médico (a expectativa por boas notícias ou o medo das más notícias). Apesar do medo, a esperança também permeou todo o processo de internação, seja na recuperação, em ver o paciente conversando, ou em receber informações positivas sobre seu estado de saúde. Além disso, a impotência apareceu de forma importante no discurso dos sujeitos e se mostrou diretamente relacionada com a experiência na UTI. Os participantes sentiam não ter o que fazer e expressavam isso de diferentes formas, inclusive na forma da barganha:

. . . Porque a gente não pode fazer nada, né, eu me sinto impotente, sabe? Eu quero ajudar, eu quero, sabe? E não tenho como fazer, o máximo que eu posso fazer é vim aqui, né, mais que isso eu não posso fazer, né. E a gente quer mais, a gente quer fazer mais, se pudesse fazer mais eu faria mais. . . (P4)

Alguns entrevistados relataram culpa pela situação de saúde do familiar e arrependimentos por não ter valorizado a companhia do paciente como, agora, gostariam:

. . como pai me sinto bastante culpado de ocorrer isso, né, com ela, por eu não estar nesse dia. . . Culpado porque se eu tivesse ali na hora eu tinha socorrido na hora, né. Então, talvez essa lesão no cérebro ocorreu pelo tempo que ela teve em coma, né... (P9) Esteve presente de forma importante, ainda, a saudade dos momentos compartilhados com o paciente, a importância para os sujeitos de objetos que lembram o familiar doente e, até mesmo, a interferência na sensação temporal, ou seja, a percepção de que durante a internação o tempo passava mais devagar:

Porque de noite eu pego e deito na cama, eu pego o travesseiro dele, eu pego o cobertor dele, eu pego uma camisa dele, eu sinto o cheiro dele e nisso eu adormeço. . . . De dia eu não consigo entrar dentro de casa, porque eu não durmo de dia. . . . Porque eu fico em casa sozinha, eu sento no sofá eu fico olhando pra casa ... Só a saudade, né, a saudade que a gente tem dele, de ver ele .. . mas eu não dei valor, não dei valor quando ele tava aqui, e ele sempre falava: "aproveita enquanto eu tô vivo, que quando eu não tiver mais aqui vocês vão sentir minha falta". Aí agora eu tô sentindo muita falta dele. (P11)

Observou-se que as emoções expressadas pelos participantes são parcialmente distintas das relatadas pela literatura (Ismael, 2004; Nieweglowski \& Moré, 2008; Severo \& Girardon-Perlini, 2005), que fez referência a sentimentos de tensão, angústia, estresse, ansiedade, raiva, medo e depressão.

Planos Pós-Alta. Esta subcategoria aponta para os planos que surgiram para depois da alta da UTI ou do hospital. Apesar de os entrevistados demonstrarem vivenciar momento em que toda 
a sua atenção estava voltada para a internação, alguns planos emergiram e dizem respeito desde à construção de projetos de vida com o próprio paciente até ao planejamento para possíveis mudanças, como o afastamento do trabalho, ambos relacionados ao pós-alta hospitalar. Entretanto, planos para o futuro mais próximo, de alta da UTI, também apareceram, como a preservação do relacionamento familiar para a internação na enfermaria e o afastamento de casa e "mudança" para o hospital para acompanhar o doente:

... A minha mala já tá pronta, na realidade, eu só não sabia quando que eu vinha pra cá. Então eles já sabem que eu vou me mudar pra cá... Eu vou ter que ficar com ela... . agora no quarto. Então eles já sabem desse quadro, né. Já avisei que final de semana se eu for é uma noite, ou um dia, caso meu irmão venha ficar com ela... (P2)

Apesar das manifestações de planos pós-alta, percebe-se que eles se mantêm relacionados ao doente e à doença, demonstrando que a atenção dos participantes durante a internação na UTI permanece focada na situação de adoecimento.

\section{Considerações Finais}

A presente pesquisa possibilitou compreender, na perspectiva de familiares, as repercussões do processo de internação em UTI Adulto enfocando na notícia da internação, nos boletins médicos, nas visitas ao paciente no leito e, nas mudanças no cotidiano familiar. Foi possível confirmar aspectos verificados previamente por alguns estudos, assim como contestar outros. Ressalta-se a importância desse trabalho por tornar possível a compreensão do impacto da internação nas famílias em situações mais específicas do processo de internação em UTI (notícia da internação, boletim médico, visita e cotidiano familiar), visto que outras pesquisas resultaram em dados mais gerais dessa experiência.

As narrativas dos familiares evidenciaram a atribuição de diferentes significados à internação de seus entes na UTI. Isso demonstrou que parte da ansiedade vivenciada estava relacionada com a imprevisibilidade atribuída a essa unidade hos- pitalar, que está associada tanto com aspectos de vida quanto de morte. Além disso, a experiência pode ressignificar a vida dos sujeitos envolvidos, segundo relatos deles próprios.

A comunicação equipe-família foi identificada como fator importante para a vivência emocional da internação, que foi facilitada quando houve um diálogo aberto e uma relação de cuidado entre profissionais e familiares. Assim como a visita ao leito que, apesar dos aspectos de desconforto ou de segurança relacionados ao espaço da UTI, tem sua importância decorrente da companhia do familiar ao doente. Ficaram evidentes nos discursos dos participantes, ainda, as transformações vivenciadas pelas famílias em seu cotidiano, que enfrentaram mudanças nas atividades de vida diárias, maior aproximação da família, além de planos para depois da alta do paciente.

A internação em UTI repercute diretamente nas famílias dos doentes, sendo assim, o cuidado da equipe multiprofissional não pode estar focado apenas no paciente, mas precisa ampliar-se para toda a sua rede. Situações estressoras, quando bem acolhidas, podem ser favorecedoras de promoção de desenvolvimento. Quando os profissionais reconhecem e compreendem as necessidades e os sentimentos dos familiares e sujeitos internados, conseguem realizar uma assistência mais qualificada e humanizada, promovendo as bases para que o efeito estressor da hospitalização seja melhor absorvido emocionalmente pelo paciente e sua família.

Percebeu-se, ao término deste trabalho, a necessidade da realização de outras pesquisas com familiares de pacientes internados em UTI. Algumas sugestões de estudos que enriqueceriam ainda mais a área são: verificar, após a alta hospitalar, as consequências da internação a longo prazo nos familiares; investigar a incidência de estresse pós-traumático nos sujeitos que vivenciam a internação; e identificar as estratégias de enfrentamento utilizadas pelos envolvidos na experiência. Observa-se a necessidade de mais pesquisas voltadas para esse público a fim de enfatizar a importância da assistência da equipe multiprofissional, culminando em um cuidado mais humanizado também aos familiares. 


\section{Referências}

Bardin, L. (1977). Análise de conteúdo. Lisboa: Edições 70 .

Barros, L. (2003). Psicologia pediátrica: Perspectiva desenvolvimentista. Lisboa: Climepsi.

Bowen, M. (1998). A reação da família à morte. In F. Walsh, Morte na familia: Sobrevivendo as perdas (pp. 105-117). Porto Alegre, RS: Artmed.

Dalgalarrondo, P. (2008). Psicopatologia e semiologia dos transtornos mentais (2. ed.). Porto Alegre, RS: Artmed.

Fontanella, B. J. B., Ricas, J., \& Turato, E. R. (2008). Amostragem por saturação em pesquisas qualitativas em saúde: Contribuições teóricas. Cadernos de Saúde Pública, 24(1), 17-27. doi:10.1590/ S0102-311X2008000100003

Freitas, K. S., Mussi, F. C., \& Menezes, I. G. (2012). Desconfortos vividos no cotidiano de familiares de pessoas internadas na UTI. Escola Anna Nery Revista de Enfermagem, 16(4), 704-711. doi:10.1590/S1414-81452012000400009

Guest, G., Bunce, A., \& Johnson, L. (2006). How many interviews are enough? An experiment with data saturation and variability. Field Methods, 18(1), 59-82. doi: $10.1177 / 1525822 X 05279903$

Ismael, S. M. C. (2004). A família do paciente em UTI. In J. de Mello Filho \& M. Burd (Eds.), Doença e família (pp. 251-257). São Paulo, SP: Casa do Psicólogo.

Lima, F. de A., Amazonas, M. C. L. de A., Barreto, C. L. B. T., \& Menezes, W. N. (2013). Sons and daughters with a parent hospitalized in an Intensive Care Unit. Estudos de Psicologia (Campinas), 30(2), 199-209. doi:10.1590/S0103$-166 \times 2013000200006$

McAdam, J. L., Dracup, K. A., White, D. B., Fontaine, D. K., \& Puntillo, K. A. (2010). Symptom experiences of family members of intensive care unit patients at high risk for dying. Critical Care Medicine, 38(4), 1078-1083. doi:10.1097/ CCM.0b013e3181cf6d94

Ministério da Saúde. (2008). Humaniza SUS: Visita aberta e direito a acompanhante (2. ed.). Brasília, DF: Autor.

Molina, R. C. M., Higarashi, I. H., \& Marcon, S. S. (2014). Importância atribuída à rede de suporte social por mães com filhos em unidade intensiva. Escola Anna Nery Revista de Enfermagem, 18(1), 60-67. doi:10.5935/1414-8145.20140009
Morgon, F. H., \& Guirardello, E. de B. (2004). Validação da escala de razão das necessidades de familiares em Unidade de Terapia Intensiva. Revista Latino-Americana de Enfermagem, 12(2), 198203. doi:10.1590/S0104-11692004000200008

Nieweglowski, V. H., \& Moré, C. L. O. O. (2008). Comunicação equipe-família em unidade de terapia intensiva pediátrica: Impacto no processo de hospitalização. Estudos de Psicologia (Campinas), 25(1), 111-122. doi:10.1590/S0103$-166 \times 2008000100011$

Rolland, J. S. (1995). Doença crônica e o ciclo de vida familiar. In B. Carter \& M. McGoldrick (Eds.), As mudanças no ciclo de vida familiar: Uma estrutura para a terapia familiar (2. ed., M. A. V. Veronese, Trad., pp. 373-392). Porto Alegre, RS: Artmed.

Severo, G. C., \& Girardon-Perlini, N. M. O. (2005). Estar internado em Unidade de Terapia Intensiva: Percepção de pacientes. Scientia Medica, 15(1), 21-29. Recuperado em http://revistaseletronicas.pucrs.br/fo/ojs/index.php/scientiamedica/article/view/1539

Silva, R. R. (2007). Psicologia e Unidade de Terapia Intensiva. Revista Salus, 1(1), 39-41. Recuperado em http://revistas.unicentro.br/index.php/ salus/article/view/668/779

Vieira, J. M., Matos, K. A. P., Andrade-Barbosa, T. L., \& Xavier-Gomes, L. M. (2013). Sentimentos vivenciados por familiares de pacientes internados no centro de terapia intensiva adulto. Revista Cubana de Enfermeria, 29(1), 18-28. Recuperado em http://scielo.sld.cu/scielo.php?script=sci arttext\&pid=S0864-03192013000100004\&lng= es\&nrm $=$ iso

Wright, L. M., \& Leahey, M. (2013). Nurses and families: A guide to family assessment and intervention ( $6^{\text {th }}$ ed.). Philadelphia, PA: Davis.

Zanetti, T. G., Stumm, E. M. F., \& Ubessi, L. D. (2013). Stress and coping in families of patients in an intensive care unit. Revista de Pesquisa: Cuidado é Fundamental Online, 5(2), 36083619. doi:10.9789/2175-5361.2013.v5i2.36083619 